\title{
Percepção de enfermeiras obstetras sobre o modelo e prática assistencial em uma maternidade filantrópica
}

Perception of obstetric nurses on the care model and practice in a philanthropic maternity hospital

Percepción de enfermeras obstétricas sobre el modelo de atención y práctica en una maternidad

filantrópica

\section{Torcata Amorim ${ }^{\mathrm{I}}$, Aline Carolina Marques Araújo' ${ }^{\mathrm{II}}$, Eliane Marina Palhares Guimarães ${ }^{\mathrm{III}}$, Solange Clessêncio Ferreira Diniz ${ }^{\mathrm{IV}}$, Helen Martins Gandrav ${ }^{\mathrm{v}}$, Maria Cecília Rodrigues Macedo Cândidovi}

\begin{abstract}
Resumo: Objetivo: conhecer a percepção de enfermeiras obstetras sobre o modelo e prática assistencial em uma maternidade filantrópica. Método: estudo qualitativo com 13 enfermeiras obstetras que trabalham em uma maternidade mineira, coleta de dados de setembro de 2015 a fevereiro de 2016 por meio de entrevista semiestruturada, utilizando-se Análise de Conteúdo. Resultados: emergiram como categorias: Atuação pautada na humanização e nas boas práticas; Autonomia para atuar; Profissional de referência para tomada de decisões; Atuação em equipe e Modelo de atuação. Discussão: verificou-se que as enfermeiras atuam com autonomia em equipe, não nomeiam um modelo de assistência e apontam a demanda de serviço e o modelo tecnocrático como dificultadores. Considerações finais: apoio e suporte dos gestores são importantes para a atuação das profissionais, contribuindo para um trabalho autônomo. Apesar dos avanços, ainda há desafios a serem superados tanto no âmbito da equipe e comunicação, quanto do suporte dos gestores.
\end{abstract}

Descritores: Autonomia profissional; Modelos de Assistência à Saúde; Enfermagem Obstétrica; Assistência ao Parto; Prática profissional

\footnotetext{
${ }^{I}$ Enfermeira Obstétrica. Doutora em Ciências pela Escola de Enfermagem da Universidade de São Paulo. Escola de Enfermagem, Universidade Federal de Minas Gerais. Belo Horizonte, Minas Gerais, Brasil. torcata@enf.ufmg.br. ORCID: https://orcid.org/0000-0002-9177-9958

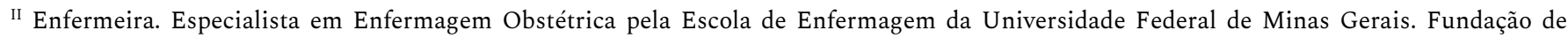
Assistência Integral a Saúde - Hospital Sofia Feldman. Belo Horizonte, Minas Gerais, Brasil. allenaraujo13@yahoo.com.br. ORCID: https://orcid.org/0000-0001-8120-7246

III Enfermeira. Doutora em Enfermagem pela Escola de Enfermagem de Ribeirão Preto/USP. Escola de Enfermagem, Universidade Federal de Minas Gerais. Belo Horizonte, Minas Gerais, Brasil. elianemg@gmail.com. ORCID: https://orcid.org/0000-0001-5270-7006

IV Enfermeira Obstetra. Mestre em Ciências da Saúde pelo Instituto de Ensino e Pesquisa da Santa Casa de Belo Horizonte. Assistência Integral a Saúde - Hospital Sofia Feldman. Belo Horizonte, Minas Gerais, Brasil. sosodiniz2005@yahoo.com.br. ORCID: https://orcid.org/0000-0002-78505565

${ }^{\vee}$ Enfermeira. Especialista em Enfermagem Obstétrica pelo Hospital Sofia Feldman. Fundação de Assistência Integral a Saúde - Hospital Sofia Feldman. Belo Horizonte, Minas Gerais, Brasil. helen.gandra@hotmail.com. ORCID: https://orcid.org/0000-0001-6861-5472

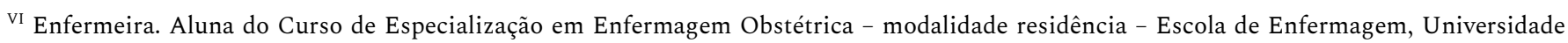
Federal de Minas Gerais. mariacmacedo@live.com. ORCID: http://orcid.org/0000-0002-9205-9987
} 


\begin{abstract}
Objective: to identify the perception of obstetric nurses about the healthcare model and practice in a philanthropic maternity hospital. Method: qualitative study of 13 obstetric nurses working in a Minas Gerais maternity hospital. Researchers used semi-structured interviews for data collection which took place from September 2015 to February 2016. Data analysis used content analysis. Results: the following categories emerged: Performance based on humanization and good practices; Professional autonomy; Professional mentoring during decision making; Teamwork and Performance Model. Discussion: research revealed that nurses are autonomous and work as a team; they did not single out a healthcare model and identified work demand and technocratic model as obstacles. Final considerations: management support is important for the professionals' performance since it contributes to autonomy at work. Despite the progress made, there are still challenges both in terms of staff and communication, as well as management support.
\end{abstract}

Keywords: Professional autonomy; Health Care Models; Obstetric Nursing; Childbirth Assistance; Professional practice

Resumen: Objetivo: conocer la percepción de las enfermeras obstétricas sobre la práctica y el modelo de atención en una maternidad de beneficencia. Método: estudio cualitativo con 13 enfermeras obstétricas de una maternidad de Minas Gerais; los datos, recogidos de septiembre de 2015 a febrero de 2016 en entrevistas semiestructuradas, se analizaron según el análisis de contenido. Resultados: se identificaron las siguientes categorías: Desempeño basado en la humanización y en las buenas prácticas; Autonomía para trabajar; Coaching para la toma de decisiones; Trabajo en equipo y Modelo de desempeño. Discusión: las enfermeras actúan con autonomía, en equipo, no mencionaron ningún modelo de atención; la demanda de servicios y el modelo tecnocrático representaban obstáculos. Consideraciones finales: el respaldo de la gerencia es fundamental para el desempeño profesional y contribuye a que se trabaje con autonomía. Aún hay retos por superar, tanto a nivel de equipos y comunicación como de respaldo de la gerencia.

Palabras clave: Autonomía profesional; Modelos de atencion de la salud: Enfermería obstétrica; Atención al parto; Práctica profesional

\title{
Introdução
}

Antigamente, a assistência ao parto e nascimento era vivenciada no domicílio, com a ajuda de uma parteira, mulher de confiança da família. ${ }^{1}$ No século $X X$, com a mudança do cenário parturitivo para a instituição hospitalar, o contexto individual e familiar foi relegado e novos atores e profissionais de saúde foram incluídos na assistência para agregar um conjunto de práticas padronizadas e intervencionistas. ${ }^{2}$ Contudo, o uso irracional e indiscriminado de tecnologias levou a um paradoxo perinatal pois, apesar de melhorar a sobrevivência dos recémnascidos, não há evidências de melhoria nos indicadores da mortalidade materna. ${ }^{3}$ 
Paralelamente, houve ascensão nas taxas de cesáreas e a adesão às tecnologias no nascimento mudou a forma de assistir, que culminaram em uma gama de intervenções no processo fisiológico da forma de parir. ${ }^{4}$ Em contrapartida ao modelo intervencionista, surge o modelo denominado como humanizado, que retoma uma assistência respeitosa com a fisiologia do parto, em que as intervenções são pautadas em critérios cientificamente comprovados, considerando os aspectos culturais, sociais e a autonomia da mulher. ${ }^{5}$

Preocupado com os indicadores de morbimortalidade materna e perinatal, e também com elevadas taxas de cesarianas, o Ministério da Saúde (MS) lança políticas buscando mudanças na forma de assistir o momento do nascimento, com resgate do parto natural. Uma dessas medidas foi o incentivo a inserção do Enfermeiro(a) Obstetra na assistência ao parto e nascimento. ${ }^{6}$ Esses profissionais valorizam a fisiologia do parto, estabelecem um equilíbrio no uso de intervenções necessárias no processo parturitivo e promovem redução das intervenções nas gestantes de risco habitual. Vale ressaltar, que o Enfermeiro(a) Obstetra assume a assistência do parto normal de risco habitual, mas em qualquer momento, caso necessite de uma avaliação e/ou situação de complicação, o médico(a) obstetra é acionado imediatamente. ${ }^{7}$

Considerando as atribuições legais do Enfermeiro(a) Obstetra no acompanhamento ao trabalho de parto e parto, as normas, portarias e resoluções contribuem para uma assistência humanizada e de qualidade, e resgatam o protagonismo da mulher no parto. Esses profissionais têm potencial para superar o modelo intervencionista, com a capacidade de propor na assistência, práticas peculiares, que promovem o cuidado individualizado e humanizado no atendimento as parturientes. ${ }^{3}$

Percebe-se que há uma lacuna de estudos nacionais que remetem a percepção de enfermeiros obstetras quanto ao modelo assistencial nas instituições hospitalares e autonomia profissional, inclusive mediante o local de atuação, meios de trabalho e relação com a equipe. 
3 | Amorim T, Araújo ACM, Guimarães EMP, Diniz SCF, Gandra HM, Cândido MCRM

Assim, objetiva-se conhecer a percepção de enfermeiras obstetras sobre o modelo e prática assistencial em uma maternidade filantrópica.

\section{Método}

Trata-se de uma pesquisa de campo descritiva e exploratória, com abordagem qualitativa. A pesquisa qualitativa permite uma avaliação mais ampla dos resultados obtidos, das possibilidades de descrição, explicação e compreensão do objeto de estudo. ${ }^{8}$

Em Belo Horizonte, Minas Gerais, algumas maternidades incentivam o trabalho em equipe multiprofissional e a atuação do Enfermeiro(a) Obstetra na assistência humanizada à mulher no ciclo gravídico puerperal. Em uma maternidade filantrópica, sem fins lucrativos, totalmente subsidiada pelo Sistema Único de Saúde (SUS) e que oferece assistência igualitária, os Enfermeiros(as) Obstetras cuidam integralmente das gestantes, parturientes, puérperas e recém-nascidos, realizando o pré-natal de risco habitual, avaliação admissional, acompanhamento no pré-parto, parto e puerpério incluindo a alta hospitalar e avaliação dos recém-nascidos. Também atuam na gestão da instituição e educação continuada da equipe.

Participaram da pesquisa enfermeiras obstetras que prestam assistência direta ao trabalho de parto, parto e puerpério em uma maternidade de um hospital filantrópico de Belo Horizonte, onde atuam sessenta e quatro enfermeiras obstetras, mas participaram da entrevista 13 profissionais.

Como critério de inclusão tem-se: os(as) enfermeiros(as) que atuavam na maternidade da instituição há dois anos ou mais, na assistência ao parto e nascimento. Foram excluídos(as) os(as) profissionais que estavam de licença saúde, maternidade, afastamento para qualificação ou que cumpriam aviso prévio. Acredita-se que o tempo de atuação contribui com a familiarização e reconhecimento do modelo de assistência que estão inseridos. 
Inicialmente foi feito contato com os possíveis participantes e, em caso de aceite, agendava-se a entrevista. Estas aconteceram na própria instituição, no intervalo de almoço, descanso ou após seu horário de trabalho, em local reservado, utilizando-se um roteiro semiestruturado como guia para alcançar os objetivos. As entrevistas aconteceram no período de setembro de 2015 a fevereiro de 2016, com duração média de 20 (vinte) minutos. Na 13ª , observou-se a saturação nas falas, ou seja, nenhuma nova informação estava sendo acrescida, dando por encerrada esta fase. No roteiro também foi possível traçar o perfil das entrevistadas. A entrevista foi composta de temas como: dados de identificação, dados profissionais, dados empregatícios na instituição, atuação como Enfermeiro(a) Obstetra, condutas tomadas no cuidado, percepção sobre a atuação no serviço e modelo assistencial da maternidade. As entrevistas foram audiogravadas e, posteriormente, transcritas na íntegra, com subsequente organização com o propósito de aprimorar o texto e excluir vícios de linguagem, assim como relatos repetidos.

Para o tratamento dos dados utilizou-se a técnica de análise de conteúdo de Bardin, conceituada como um conjunto de técnicas que objetivam analisar as comunicações por meio de procedimentos sistemáticos, descrevendo o conteúdo das mensagens. ${ }^{9}$ Este processo de análise seguiu as etapas: 1) pré-análise, que envolve a realização de leitura flutuante, com a familiarização do conteúdo; 2) exploração do material, na busca por melhores interpretações e inferências e 3) Tratamento dos resultados, com a seleção de informações relevantes após análise crítica e reflexiva. ${ }^{9}$

Buscando manter o sigilo, os nomes das participantes foram substituídos por codinomes de Deusas Gregas, definidos pelo pesquisador. Utilizou-se o critério de saturação teórica, operacionalmente definido como suspensão de inclusão de novos participantes, que acontece quando os dados obtidos passam a apresentar, na avaliação do pesquisador, certa redundância ou repetição, não sendo considerado relevante persistir na coleta de dados. ${ }^{10} \mathrm{O}$ estudo respeitou 
5 | Amorim T, Araújo ACM, Guimarães EMP, Diniz SCF, Gandra HM, Cândido MCRM

a Resolução 466/12 do Conselho Nacional de Saúde que trata da pesquisa em seres humanos. O projeto foi submetido ao Comitê de Ética em Pesquisa da Universidade Federal de Minas Gerais e aprovado sob parecer $\mathrm{n}^{\mathbf{0}}$ 39444614.6.0000.5149 em 01 de abril de 2015. As entrevistadas assinaram o Termo de Consentimento Livre e Esclarecido em duas vias, sendo uma das participantes e a outra da pesquisadora.

\section{Resultados e discussão}

O perfil das 13 participantes foi apresentado quantitativamente e na tabela 1 a seguir, é apresentada a caracterização das Enfermeiras Obstetra.

Tabela 1 - Caracterização das enfermeiras obstetras de uma maternidade filantrópica de Belo Horizonte. 2016. $\mathrm{N}=13$

\begin{tabular}{lll}
\hline Variáveis de caracterização & n & \% \\
\hline Idade & 5 & 38 \\
30-34 anos & 3 & 24 \\
35-39 anos & 3 & 38 \\
$\geq 40$ anos & & \\
Sexo & 13 & 100 \\
Feminino & & \\
Tempo de formação na especialidade & 9 & 69 \\
7-10 anos & 4 & 31 \\
11-14 anos & & \\
Tempo de trabalho na instituição & 8 & 61 \\
5-10 anos & 4 & 31 \\
11-16 anos & 1 & 8 \\
$\geq 17$ anos & & \\
Carga horária & 3 & 23 \\
24-30 horas & 3 & 23 \\
31-37 horas & & 54 \\
$\geq 38$ horas & 7 &
\end{tabular}

\section{Atividades desenvolvidas}

Assistência ao parto 
Percepção de enfermeiras obstetras sobre o modelo e prática assistencial ... |6

\begin{tabular}{|c|c|c|}
\hline $\begin{array}{l}\text { Assistência ao parto e gerência/ } \\
\text { coordenação }\end{array}$ & 2 & 15 \\
\hline $\begin{array}{l}\text { Assistência ao parto, gerência/ } \\
\text { coordenação e ambulatório de saúde da } \\
\text { mulher }\end{array}$ & 1 & 8 \\
\hline $\begin{array}{l}\text { Assistência ao parto e outras áreas } \\
\text { rabalha também em outras instituições }\end{array}$ & 4 & 31 \\
\hline $\operatorname{Sim}$ & 5 & 38 \\
\hline Não & 8 & 62 \\
\hline
\end{tabular}

Fonte: Dados levantados pelas autoras, 2016.

Com a imersão nas entrevistas emergiram cinco categorias: Atuação pautada na humanização e nas boas práticas, Autonomia para atuar, Profissional de referência para tomada de decisão, Atuação em equipe, Modelo de atuação.

\section{Atuação Pautada na Humanização e nas Boas Práticas}

Nesta categoria, as entrevistadas remetem a uma assistência baseada nos princípios da humanização e das boas práticas. A humanização para elas está ligada ao ato de respeitar o desejo da parturiente, seja na escolha do acompanhante, na posição de parir e na fisiologia do parto, conforme os fragmentos:

Minha atuação na assistência às pacientes de modo geral, é focada conforme as necessidades delas, respeitando sempre aquilo que ela está precisando. Busco saber se ela tem um plano de parto, como está desenvolvendo o trabalho de parto, não esquecendo o lado da mulher, o lado do companheiro. (Leto)

Direito da mulher de deambular, tomar banho de chuveiro, fazer ingestão de líquidos, ficar na bola, ter direito à um acompanhante, das boas práticas. (Gaia)

Os relatos também expõem a necessidade de melhorias na assistência e mostram dificuldades relacionadas à demanda de serviço e na atitude de alguns profissionais que não 
7 | Amorim T, Araújo ACM, Guimarães EMP, Diniz SCF, Gandra HM, Cândido MCRM

incorporaram a filosofia adotada na instituição, ou seja, as boas práticas. Estas situações revelam fragilidades que podem comprometer a assistência.

A gente percebe que alguns colegas não têm essa filosofia de trabalho [...] Contato pele a pele, presença de acompanhante, escolha de posição no parto. Alguns profissionais que vem de outras instituições, ainda não absorveram essa prática da humanização. Quando os profissionais médicos não praticam a humanização, ocorrem conflitos com a equipe. Então, às vezes, a gente tem alguns embates, principalmente com os médicos que não conhecem totalmente os protocolos. As vezes temos que intervir em algumas condutas por exemplo, manobra de kristeller. Essas condutas atrapalham um pouco a humanização, mas a gente acredita que com o tempo, vão abraçar esta causa. (Selene)

[...] É uma assistência humanizada, de referência e de excelência [...], que tem muito que melhorar por causa da nossa demanda [de trabalho], mas, tem bons resultados e eu acredito que a tendência é melhorar. (Artemis)

As Enfermeiras Obstetras relataram atuar com autonomia, buscando a humanização e as boas práticas. Reconhecem a importância do seu trabalho e de desenvolvê-lo em equipe. Buscam oferecer uma assistência que promova resultados satisfatórios e positivos, tanto para a mãe quanto para o concepto.

Para humanizar a assistência obstétrica devem ser garantidas as relações interpessoais com a mulher, recém-nascido e acompanhante, bem como a promoção de situações apropriadas para atender as peculiaridades de cada mulher na assistência ao parto e nascimento. ${ }^{11}$ No processo parturitivo, deve-se assegurar atenção de qualidade e humanizada com adoção das boas práticas na assistência ao trabalho de parto e nascimento. Em estudo realizado em maternidades públicas do Rio de Janeiro, na maternidade A foram realizados 3.197 partos, na maternidade B 2.190, constatou-se que a assistência ao parto por enfermeiro obstetra apresenta percentuais maiores de técnicas não intervencionistas como os métodos não farmacológicos para alívio da dor, massagens $(1.014=34,80 \%)$ e água morna por meio do banho de aspersão $(684$ = 23,48\%), o incentivo da deambulação/movimentação livremente (1.616 = 55,48\%) e exercícios 
com movimentos pélvicos $(573=19,67 \%)$, bem como o apoio emocional, ${ }^{1}$ corroborando com os relatos das entrevistadas do presente estudo, que buscam atender as necessidades das parturientes.

A demanda do serviço e as dificuldades do trabalho em equipe mostram fragilidades que influenciam negativamente na assistência. Ressalta-se que um fator de fragilidade na relação do enfermeiro com a equipe é a comunicação, pois esta possibilita o direcionamento da prática profissional do enfermeiro com os outros profissionais, que também estão inseridos na atenção à saúde da população. ${ }^{12}$

A sobrecarga de trabalho interfere e prejudica a qualidade da assistência, e pode levar a sentimentos de intolerância, stress, cobranças pessoais, esgotamento físico e frustações nos membros da equipe. Estas situações podem ser desencadeadas pelos profissionais que não conseguem estabelecer o cuidado da maneira que gostariam. Isto pode levar a desmotivação e a insatisfação no exercício da profissão. ${ }^{13-14}$

A humanização do parto remete as entrevistadas às escolhas da parturiente, seu acompanhante, a redução de condutas intervencionistas e a atenção ao parto fisiológico. Entretanto, chama atenção a falta de relatos de sua atuação na assistência aos partos operatórios humanizados. Infere-se, assim, que a percepção das enfermeiras sobre a atuação humanizada foi direcionada, neste estudo, a assistência ao parto vaginal de risco habitual. Também nesta categoria, as enfermeiras obstetras referem as relações conflitantes entre colegas enfermeiras e

com outras categorias profissionais, em especial o médico obstetra, fato que prejudica a assistência integral, qualificada e humanizada, além de dificultar o trabalho harmônico da equipe.

\section{Autonomia para atuar}

Nesta categoria convergiram os depoimentos das Enfermeiras Obstetras que acreditam estar atuando de maneira autônoma e prestando assistência contínua e integral às mulheres. O 
9 | Amorim T, Araújo ACM, Guimarães EMP, Diniz SCF, Gandra HM, Cândido MCRM

vínculo com as clientes tem início no pré-natal, perpassa a admissão, trabalho de parto, parto e puerpério, tratamento de intercorrências e alta hospitalar. Afirmam ter conhecimento e competência para desenvolver assistência em todas estas etapas do ciclo gravídico puerperal.

[...] Temos muita autonomia desde o pré-natal, na admissão para internar as pacientes, temos esta capacidade, acompanhamento do trabalho de parto e no parto até a alta desta paciente. Considero uma assistência completa, nos casos de risco habitual. (Medusa)

As profissionais utilizam do seu conhecimento e constante aprendizado para as tomadas de decisões e acreditam que o apoio institucional é um fator facilitador e provedor desta autonomia, uma vez que disponibiliza protocolos e educação continuada, conforme se pode constatar a seguir:

[...] um trabalho de parto de risco habitual onde eu tenho autonomia de acompanhar esta mulher. No baixo risco, a gente consegue tomar decisões de acordo com o que está estabelecido na instituição (Medusa).

[...] a gente consegue atingir esse objetivo por causa das condições que são criadas aqui dentro, a questão da autonomia do enfermeiro obstetra, da divulgação dos protocolos, da atualização do nosso conhecimento o tempo todo, isso favorece muito a nossa atuação. (Hecate)

A autonomia e o trabalho integral são fatores que contribuem para o sucesso da assistência. O enfermeiro tem a liberdade da tomada de decisões e escolhas, mas é necessário que suas atitudes sejam diferenciadas, pautadas na ética e no conhecimento, além da habilidade na resolução dos problemas. ${ }^{14}$ Desta maneira, infere-se que o enfermeiro autônomo promove bons resultados, gera credibilidade e respeito perante a equipe e clientes.

A autonomia é obtida por meio da formação de qualidade. Para tanto, são necessários conhecimentos delineados com estudos atualizados e com diretrizes internacionais, buscando melhoria na prática assistencial, habilidades e atitudes perante o trabalho desenvolvido. ${ }^{15} \mathrm{~A}$ 
atualização do profissional da enfermagem, por meio da educação permanente propicia melhorias no processo de trabalho, no cuidado prestado, assim como na interação com a equipe multiprofissional e instituição, com a manutenção das experiências e saberes previamente adquiridos na prática assistencial. ${ }^{16}$

Diante dos relatos acerca da autonomia, pode-se concluir que o conhecimento confere confiança na atitude assistencial, principalmente quando o profissional tem o respaldo institucional e protocolos atualizados, assim como, acesso facilitado a sua atualização. Vale ressaltar que o Conselho da Categoria também confere respaldo para a autonomia e tomada de decisões do enfermeiro obstetra, o que pode ser identificado nas afirmativas das entrevistadas.

\section{Profissional de referência para tomada de decisão}

Nesta categoria, as entrevistadas abordaram a sua atuação nas intercorrências e na condução dos casos de risco. Relataram que, inicialmente, utilizam os critérios estabelecidos no protocolo da instituição para o direcionamento dos casos e, quando necessário, recorrem às enfermeiras obstetras com mais experiência e à equipe médica.

[...] Acompanhando o trabalho de parto ou caso clínico, seja lá qual for a situação, qualquer intercorrência que tenha que saia da normalidade, é baseado na sequência do protocolo. A gente discute o caso com o profissional no plantão, quer seja enfermeiro(a) obstetra, o [médico] obstetra ou outro profissional, dependendo da situação. (Sofia)

[...] Os casos são discutidos com o [médico] obstetra de plantão e na própria equipe de enfermeiros obstetras é super tranquilo as discussões. (Selene).

A presença de um enfermeiro capacitado e experiente na assistência à parturiente confere segurança e confiança às mulheres, fato este que contribui para o enfrentamento do trabalho de parto com tranquilidade, paciência e conforto. ${ }^{14}$ Do mesmo modo, o Enfermeiro(a) Obstetra em sua atuação, apresenta autonomia atrelada a tomada de decisão para um melhor gerenciamento 
do cuidado e compartilhamento com a equipe, nas decisões que envolvem a assistência ao préparto, parto e puerpério. ${ }^{12}$

A tomada de decisão e autonomia foram requisitos vistos em enfermeiros obstetras em estudo desenvolvido na Irlanda que buscou conhecer um modelo da prática especializada e avançada desses profissionais, bem como os benefícios na assistência a mulher e bebê com a atuação conjunta do enfermeiro obstetra com a equipe médica. Ainda revelou a adoção de um cuidado holístico e atencioso, com desfechos clínicos positivos. ${ }^{17}$

As entrevistadas referem em seus relatos, sua autonomia e integração da equipe nas intercorrências. Ressaltam a importância dos protocolos que favorecem uma tomada de decisão segura, como também a troca de saberes com os colegas de plantão. Isto contribui para um trabalho resolutivo e de qualidade no cuidado às parturientes de alto risco.

\section{Atuação em equipe}

As participantes da pesquisa de modo geral, expressam visões muito próximas da sua atuação em equipe. Foram unânimes ao relatar que as decisões são tomadas em conjunto e reconhecem a importância do envolvimento de diferentes profissionais. Expressam que na assistência a gestante de risco, há a atuação dos médicos, porém é importante a participação do Enfermeiro(a) Obstetra.

[...] A gente só consegue que essa equipe funcione, e o objetivo final do nosso trabalho é que a mulher seja atendida com qualidade no parto e um nascimento com resultado de excelência, se toda a equipe estiver participando. Então, temos que ter uma equipe harmônica, equilibrada, na qual todos os profissionais estejam falando a mesma língua, estejam participando. Então essa atuação do enfermeiro obstetra na equipe tem que manter essa corrente unida, firme. (Atena)

[...] As decisões, na maioria das vezes, são tomadas em equipe, raríssimas as vezes que a gente toma decisão sozinha. Trabalhamos junto com o 
profissional médico, então as decisões são tomadas juntamente com eles. (Pandora)

\section{[...] O EO tem um papel importante da equipe. (Ariadne)}

O Enfermeiro(a) Obstetra deve buscar atuar no modelo colaborativo, que conta com a cooperação de todos os envolvidos no cuidado e, quando a equipe está unida, os desafios são superados com maior facilidade. A colaboração de todos reforça a troca de experiências e agrega novos conhecimentos. ${ }^{13} \mathrm{O}$ trabalho multiprofissional é a união dos membros da equipe, e cada indivíduo interage por meio da comunicação e articulação das técnicas assistenciais para as tomadas de decisão. O trabalho em saúde reconhece o trabalho do outro e requer o estabelecimento de uma relação entre os envolvidos, mediado pela comunicação e sustentado pelo respeito e ética entre os profissionais, possibilitando assim, compreender a importância de implementar uma assistência sistematizada e em consonância com os envolvidos no serviço. ${ }^{18}$

Os relatos sugerem que os profissionais devem primar pela qualidade da assistência em equipe, bem como, para a sua convivência, troca de saberes e tomada de decisão conjunta. Para tanto, cada um dos profissionais tem importância singular e papel de destaque no acompanhamento do trabalho de parto, parto e puerpério.

\section{O modelo de atuação}

Ao serem questionadas como definem o modelo de assistência da instituição, as entrevistadas não nomeiam um modelo, mas revelam prestar uma assistência pautada na humanização, reforçando que estão inseridas no modelo de trabalho em equipe.

[...] Assistência baseada nas boas práticas. (Gaia)

[...] Defino como multiprofissional. (Sofia)

[...] Modelo de humanização. (Afrodite)

[...] Respeito à mulher no momento do nascimento (Selene). 
Apesar de não especificarem um modelo de atuação, as entrevistadas salientam buscar qualidade, humanização e satisfação das mulheres, o que possibilitou observar que no cenário estudado, a atuação das profissionais tem aproximação com o modelo humanístico. Neste modelo, o indivíduo é visto como um ser de necessidades biológicas, sociais, psicológicas e espirituais. ${ }^{19}$

No modelo humanístico, o parto é visto como um processo fisiológico que precisa ser acompanhado. Há uma abordagem biopsicossocial do evento, valorização dos aspectos afetivos e culturais e o uso racional da tecnologia, bem como maior satisfação da usuária que participa e é protagonista do evento. ${ }^{20} \mathrm{O}$ profissional interage com a parturiente, passa informações para ela e a responsabilidade das tomadas de decisão é compartilhada. A ciência e a tecnologia são associadas ao seu uso equilibrado, às evidências científicas, ao desejo da mulher e da família e à humanização. O processo de parto e nascimento é assistido por uma equipe multiprofissional. ${ }^{21}$

Os relatos também remetem a uma nova perspectiva do cuidado na área da saúde com abordagem do trabalho colaborativo, no qual os profissionais estendem as relações do cuidado aos pacientes e familiares. Este modelo permite que os cuidadores de saúde trabalhem em equipe, construindo um clima de parceria e ajuda mútua. ${ }^{13}$ Assim, acredita-se que esta forma de trabalho resulta em vários benefícios, repercutindo positivamente na qualidade da assistência e na satisfação do cliente e dos profissionais.

\section{Considerações finais}

Vários foram os avanços da assistência obstétrica no Brasil, dentre eles destaca-se a reinserção dos profissionais Enfermeiros(as) Obstetra no cenário de assistência ao ciclo gravídico puerperal. A atuação dessas profissionais é reconhecida pela assistência baseada em boas práticas, no respeito a fisiologia do parto e nascimento e por ser menos intervencionista. 
O estudo revelou que as enfermeiras obstetras se vêem inseridas no trabalho em equipe, valorizam o diálogo como mecanismo importante para a interação dos profissionais e reconhecem a importância dos diferentes atores na condução do trabalho, sobretudo a necessidade da sua participação, enquanto especialista. Avaliam que os gestores são importantes provedores para sua atuação, incentivando e valorizando seu trabalho, sendo o apoio institucional um facilitador para a atuação da enfermagem obstétrica e da equipe multiprofissional, contribuindo ainda para sua autonomia e adoção das boas práticas.

A sobrecarga de trabalho e as divergências quanto às condutas que porventura geram conflitos na equipe, podem ser resolvidas ou minimizadas com o aumento do quantitativo e qualificação de profissionais, em especial enfermeiros obstetras, o que também contribui para potencializar sua atuação.

A autonomia profissional é reafirmada pela presença dos Enfermeiros(a) Obstetras em diferentes espaços e níveis de complexidade de assistência e por meio de atualizações que devem ser promovidas e incentivadas pela instituição e pautadas nas evidências científicas. Os protocolos são importantes ferramentas que padronizam e auxiliam nas tomadas de conduta.

O presente estudo foi desenvolvido em uma única instituição, limitando assim seus resultados. Portanto, faz-se necessário investigar outros locais de atuação e assim, conhecer os modelos de atenção obstétrica adotado nas maternidades, bem como contribuir com a inserção e atuação das enfermeiras especialistas em equipe multiprofissional.

Espera-se que os resultados deste contribuam para superação de desafios para inserção e atuação da enfermagem obstétrica, tanto no âmbito da equipe quanto dos gestores e igualmente, subsidia estudos relativos a prática profissional. Faz-se necessário ainda, criar estratégias para superação dos conflitos e avançar no modelo colaborativo e humanístico de assistência. 
Teve-se como limitador a não comparação dos resultados com os de outras instituições com a atuação desses(as) profissionais, o que poderia contribuir e ampliar as proposições advindas do estudo.

\section{Referências}

1. Vargens OMC, Silva ACV, Progianti JM. Contribuição de enfermeiras obstétricas para consolidação do parto humanizado em maternidades no Rio de Janeiro, Brasil. Esc Anna Nery Rev Enferm [Internet]. $2017 \mathrm{fev}$ [acesso em 2018 maio 11];21(1):1-8. Disponível em: http://www.scielo.br/scielo.php?pid=S141481452017000100215\&script=sci_abstract\&tlng=pt doi: 10.5935/1414-8145.20170015

2. Gomes ARM, Pontes DS, Pereira CCA, Brasil AOM, Moraes LCA. Assistência de enfermagem obstétrica na humanização do parto normal. Rev Recien [Internet]. 2014 [acesso em 2018 maio 10];4(11):23-7. Disponível em: https://www.recien.com.br/index.php/Recien/article/view/73/137

3. Sousa AMM. Práticas obstétricas na assistência ao parto e nascimento em uma maternidade de Belo Horizonte [dissertação]. Belo Horizonte: Universidade Federal de Minas Gerais; 2013. 139 p.

4. Leal MC, Pereira APE, Domingues RMSM, Theme Filha MM, Dias MAB, Nakamura-Pereira M, et al. Intervenções obstétricas durante o trabalho de parto e parto em mulheres brasileiras de risco habitual. Cad Saúde Pública [Internet]. 2014 ago [acesso em 2018 maio 10];30(1):17-31. Disponível em: http://www.scielo.br/pdf/csp/v30s1/0102-311X-csp-30-s1-0017.pdf doi: 10.1590/0102-311X00151513

5. Oliveira JC, Paula ACS, Garcia ESGF, Andrade MBT, Leite EPRC. Assistência obstétrica no processo de parto e nascimento. Rev Pesqui Cuid Fundamen [Internet]. 2018 abr-jun [acesso em 2018 jun 12];10(2):450-7. Disponível em: http://www.seer.unirio.br/index.php/cuidadofundamental/article/view/6083 doi: http://dx.doi.org/10.9789/2175-5361.2018.v10i2.450-457

6. Freire HSS, Campos FC, Castro RCMB, Costa CC, Mesquita VJ, Viana RAA. Parto normal assistido por enfermeira: Experiência e satisfação de puérperas. Rev Enferm UFPE [Internet]. 2017 jun [acesso em 2018 jun 12];11(6):2357-67. Disponível em: https://periodicos.ufpe.br/revistas/revistaenfermagem/article/viewFile/23398/19057 doi: 10.5205/reuol.10827-96111-1-ED.1106201714

7. Vogt SE, Silva KS, Dias MAB. Comparação de modelos de assistência ao parto em hospitais públicos. Rev Saúde Pública [Internet]. 2014 [acesso em 2018 ago 18];48(2):304-13. Disponível em: http:/www.scielosp.org/pdf/rsp/v48n2/0034-8910-rsp-48-2-0304.pdf 10.1590/S00348910.2014048004633 
8. Turato ER. Métodos qualitativos e quantitativos na área da saúde: definições, diferenças e seus objetos de pesquisa. Rev Saúde Pública [Internet]. 2005 [acesso em 2017 maio 14];39(3):507-14. Disponível em: http://www.scielo.br/pdf/rsp/v39n3/24808.pdf doi: 10.1590/S0034-89102005000300025

9. Bardin L. Análise de conteúdo. Edições 70; 2011.

10. Fontanela BJB, Ricas J, Turato ER. Amostragem por saturação em pesquisas qualitativas em saúde: contribuições teóricas. Cad Saúde Pública [Internet]. 2008 [acesso em 2017 maio 14];24(1):17-27. Disponível em: http://www.scielo.br/pdf/csp/v24n1/02.pdf doi: 10.1590/S0102-311X2008000100003

11. Gomes ARM, Pontes DS, Pereira CCA, Brasil AOM, Moraes LCA. Assistência de enfermagem obstétrica na humanização do parto normal. Rev Recien. 2014;4(11):23-7.

12. Copelli FHS, Oliveira RJT, Santos JLG, Magalhães ALP, Gregório VRP, Erdmann AL. Care management and nursing governance in a maternity ward: grounded theory. Rev Bras Enferm [Internet]. 2017 [acesso em 2018 ago 14];70(6):1247-53. Disponível em: http://www.scielo.br/scielo.php?script=sci_arttext\&pid=S0034-71672017000601277 doi: 10.1590/0034-71672016-0116

13. Waldow VR. Cuidado colaborativo em instituições de saúde: a enfermeira como integradora. Texto \& Contexto Enferm [Internet]. 2014 [acesso em 2018 ago 14];23(4):1145-52. Disponível em: http://www.scielo.br/pdf/tce/v23n4/pt_0104-0707-tce-23-04-01145.pdf 10.1590/010407072014001840013

14. Oliveira RJT, Copelli FHS, Pestana AL, Santos JLG, Gregório VRP. Condições intervenientes à governança da prática de enfermagem no centro obstétrico. Rev Gaúch Enferm [Internet]. 2014 mar [acesso em 2018 ago 16];35(1):47-54. Disponível em: http://seer.ufrgs.br/RevistaGauchadeEnfermagem/article/view/43125/28929 doi:10.1590/19831447.2014.01.43125

15. Duarte SJH, Machado RM. Competencias esenciales de la formación en obstetricia. Rev Panam Salud Pública [Internet]. 2016 nov [acesso em 2019 mar 14];40(5):382-7. Disponível em: https://www.scielosp.org/scielo.php?script=sci_arttext\&nrm=iso\&lng=pt\&tlng=pt\&pid=S102049892016001100382

16. Lima AM, Castro JFL. Educação permanente em saúde: uma estratégia para a melhoria das práticas obstétricas. Enferm Obstét [Internet]. 2017 [acesso em 2018 set 13];4:e56. Disponível em: http://www.enfo.com.br/ojs/index.php/EnfObst/article/view/56

17. O'Connor L, Casey M, Smith R, Fealy GM, Brien D, O'Leary D, et al. The universal, collaborative and dynamic model of specialist and advanced nursing and midwifery practice: a way forward? J Clin Nurs [Internet]. 2018 mar [acesso em 2019 mar 14];27(5-6):e882-e894. Disponível em: https://onlinelibrary.wiley.com/doi/full/10.1111/jocn.13964 doi: https://doi.org/10.1111/jocn.13964 
18. Oliveira JDG, Campo TNC, Souza FMLC, Davim RMB, Dantas JC. Percepção de enfermeiros obstetras na assistência à parturiente. Rev Enferm UFPE [Internet]. 2016 out [acesso em 2018 ago 16]; 10(10):3868-75. Disponível

em: https://periodicos.ufpe.br/revistas/revistaenfermagem/article/view/11454/13277 doi: 10.5205/reuol.966787805-1-ED1010201619

19. Bellaguarda MLR, Padilha MI, Pereira Neto AF, Pires D, Peres MAA. Reflexão sobre a legitimidade da autonomia da enfermagem no campo das profissões de saúde à luz das ideias de Eliot Freidson. Esc Anna Nery Rev Enferm [Internet]. 2013 abr-jun [acesso em 2018 ago 25];17(2):369-74. Disponível em: http://www.scielo.br/scielo.php?script=sci_arttext\&pid=S1414-81452013000200023 doi: 10.1590/S141481452013000200023

20. Davis-Floyd R. The technocratic, humanistic, and holistic paradigms of childbirth. Int J Gynaecol Obstet. 2001 nov;75(1):5-23.

21. Lima MFG, Pequeno AMC, Rodrigues DP, Carneiro C, Morais APP, Negreiros FDS. Developing skills learning in obstetric nursing: approaches between theory and pratice. Rev Bras Enferm [Internet]. 2017 [acesso em 2018 ago 25];70(5):1054-60. Disponível em: http://www.scielo.br/scielo.php?script=sci_arttext\&pid=S0034-71672017000501054 doi: 10.1590/0034-71672016-0665

\section{Autor correspondente}

Torcata Amorim

E-mail: torcata@enf.ufmg.br.

Endereço: Escola de Enfermagem - UFMG. Av. Prof. Alfredo Balena, 190, Santa Efigênia, Belo Horizonte, Minas Gerais, Brasil.

CEP: $30130-100$

\section{Contribuições de Autoria}

1 - Torcata Amorim

Concepção e planejamento do projeto de pesquisa; Obtenção ou análise dos dados; Interpretação dos dados; Redação; Revisão crítica.

2 - Aline Carolina Marques Araújo

Concepção e planejamento do projeto de pesquisa; Obtenção ou análise dos dados; Interpretação dos dados; Redação.

3 - Eliane Marina Palhares Guimarães

Interpretação dos dados; Revisão crítica. 
4 - Solange Clessêncio Ferreira Diniz

Interpretação dos dados; Revisão crítica.

5 - Helen Martins Gandra

Interpretação dos dados; Redação; Revisão crítica.

6 - Maria Cecília Rodrigues Macedo Cândido

Interpretação dos dados; Redação; Revisão crítica.

\section{Como citar este artigo}

Amorim T, Araújo ACM, Guimarães EMP, Diniz SCF, Gandra HM, Cândido MCRM. Percepção de enfermeiras obstetras sobre o modelo e prática assistencial em uma maternidade filantrópica. Rev. Enferm. UFSM. 2019 [Acesso em: Anos Mês Dia];vol e2: Px-Px. DOI:https://doi.org/10.5902/2179769234868 